\title{
BCL6/BCL2 and MYC Alterations Drawing the Gray Zone between Diffuse Large B-cell Lymphoma and Double, Triple Hit Lymphoma
}

Salamoon $\mathbf{M}^{*}$

Al-Bairouni University Cancer Center, Damascus, Syria

*Corresponding author: Dr. Maher Salamoon, Al-Bairouni University Cancer Center, Damascus, Syria, Tel: +963 933771086; E-mail: maher.salamoon@gmail.com Rec date: February 11, 2018; Acc date: March 01, 2018; Pub date: March 05, 2018

Copyright: () 2018 Salamoon M. This is an open-access article distributed under the terms of the creative commons attribution license, which permits unrestricted use, distribution, and reproduction in any medium, provided the original author and source are credited.

\begin{abstract}
Diffuse large B-cell lymphoma (DLBCL) Diffuse large B-cell lymphoma (DLBCL) is an aggressive type of nonHodgkin lymphoma that develops from the B-cells in the lymphatic system. Under the microscope, large malignant lymphocytes are seen diffusely throughout the specimen. Diffuse Large B-Cell Lymphoma (DLBCL) accounts for 20$30 \%$ of all lymphoid malignancies. This subtype forms distinct morphological, molecular, and phenotypic variants. Therefore, it is of a great value to classify diffuse large B-cell lymphoma according to gene expression profiling into germinal center B-cell subtype, activated B-cell subtype, and unclassified subtype. The outcomes vary between these subtypes, and the germinal center B-cell subtype has a better outcome with the current standard rituximab, cyclophosphamide, hydroxydaunorubicin, vincristine, and prednisone (R-CHOP) immunochemotherapy.
\end{abstract}

Keywords: $B C L 6 ; M Y C$ diffuse large B-cell; Lymphoma; Double hit; Gray zone

\section{Introduction}

Diffuse Large B-Cell Lymphoma (DLBCL) accounts for 20-30\% of all lymphoid malignancies. This subtype forms distinct morphological, molecular, and phenotypic variants $[1,2]$. However, most cases are classified as diffuse large B-cell lymphoma, not otherwise specified, because these cases do not meet the criteria of the World Health Organization classification system [1]. Therefore, it is of a great value to classify diffuse large B-cell lymphoma according to gene expression profiling into germinal center B-cell subtype, activated B-cell subtype, and unclassified subtype [3-5]. The outcomes vary between these subtypes, and the germinal center B-cell subtype has a better outcome with the current standard rituximab, cyclophosphamide, hydroxydaunorubicin, vincristine, and prednisone (R-CHOP) immunochemotherapy [5]. However, gene expression profiling does not capture all the biological parameters influencing diagnosis, clinical outcome, and response to therapy, nor is this modality feasible in daily practice. It is believed that DLBCL comprises multiple, unrecognized disease entities. This marked heterogeneity reflects in part the complex molecular pathogenesis of this disease, which includes specific lesions (i.e., rearrangement of the $B C L 6$ gene) as well as alterations common to other non-Hodgkin's lymphoma subtypes. Much more work should be carried out to reach the best protocol to treat this kind of aggressive lymphoma since it is still treated with old standards.

\section{Literature Review}

\section{BCL6 locus alterations}

Chromosomal translocations affecting band 3q27 represent the most common and specific genetic abnormality associated with de novo diffuse large B- cell lymphoma. These alterations were shown to be "promiscous" in that they involved balanced, reciprocal recombinations between the $3 \mathrm{q} 27$ region, containing the $B C L 6$ locus and various alternative chromosomal partners in different diffuse large B-cell lymphoma cases. The partner sites include, but are not limited to, those harboring the Ig heavy $(14 q 32)$ or light $(2 \mathrm{p} 11,22 \mathrm{q} 11)$ chain genes [6]. The BCL6 gene encodes for a $95-\mathrm{kD}$ nuclear phosphoprotein belonging to the POZ/zinc-finger family of transcription factors. In the $\mathrm{B}$-cell lineage, expression of the $B C L 6$ protein is restricted to germinal center cells, whereas it is absent in the pre-germinal center B-cells or in their differentiated progenies such as memory B-cells and plasma cells. Mice deficient for $B C L 6$ are not able to form germinal centers in response to T-cell-dependent antigens, and consequently, completely lack affinity maturation. Therefore, BCL6 seems to be a master regulator of germinal center development $[6,7]$.

Rearrangement of $B C L 6$ gene caused by chromosomal translocation is found in about $35 \%$ of diffuse large B-cell lymphoma cases. These rearrangements juxtapose the intact coding domain of BCL6 downstream and in the same transcriptional orientation to heterologous sequences derived from the partner chromosome, including $\operatorname{IgH}(14 \mathrm{q} 23)$, Igא (2p11), $\operatorname{Ig} \lambda(22 \mathrm{q} 11)$, and at least 20 other chromosomal sites unrelated to Ig loci [8].

In addition to chromosomal alterations, the 5' regulatory sequences of $B C L 6$ can be altered by multiple somatic mutations in up to $75 \%$ of diffuse large B-cell lymphoma cases. These mutations are introduced in normal germinal center cells and are believed to be generated by the same somatic hypermutations that target Ig genes. However, the full extent of BCL6 mutations deregulating gene expression has not been characterized, indicating that the fraction of diffuse large B-cell lymphoma carrying abnormal BCL6 expression cannot be determined [8].

\section{Aberrant somatic hypermutations}

Aberrant activity of somatic hypermutations is found in $50 \%$ of diffuse large B-cell lymphoma. Several proto-oncogenes are targeted by this aberrant activity, such as c-MYC, PIM1, PAX5 and RhoH/TTF. This mechanism is responsible in part for the heterogeneity of diffuse 
large B-cell lymphoma via the alteration of different cellular pathways in different cases $[9,10]$.

\section{C-MYC gene status}

The translocation $\mathrm{t}(8 ; 14)(\mathrm{q} 24.1 ; \mathrm{q} 32)$, juxtaposing the C-MYC (MYC) gene to the immunoglobulin heavy chain (IGH) gene promoter, was the first translocation detected in lymphoid neoplasms [11]. It can be identified in almost all cases of endemic Burkitt lymphoma, $30-50 \%$ of unclassifiable B-cell lymphomas with features intermediate between diffuse large B-cell lymphoma and Burkitt lymphoma and in a smaller percentage of cases of diffuse large B-cell lymphoma, not otherwise specified [10,11]. In some cases of diffuse large B-cell lymphoma, rearrangements of the $M Y C$ gene were discovered in approximately $5 \%$ to $10 \%$ of cases. Of these, $20 \%$ to $30 \%$ may have an additional break in the $B C L 2$ and/or $B C L 6$ gene, fulfilling the criteria of the so-called genetic double-hit lymphoma [12]. The prognostic significance of $M Y C$ translocations in de novo diffuse large B-cell lymphomas, the gold standard for identifying such cases, their clinicopathological context, and gene expression profile are still debatable. More recently, the prognostic significance of $M Y C$ translocations has been challenged by the recognition of the so-called phenotypic double-hit diffuse large B-cell lymphoma [13].

\section{Which patient is at increased risk?}

The 2016 revision of the WHO classification for lymphoma has included a new category of lymphoma, separate from DLBCL, termed high-grade B-cell lymphoma with translocations involving $M Y C$ and $B C l-2$ or $B C l-6$ [14]. Such cases are referred to as double-hit lymphoma (when $M Y C$ translocation is present with either the $B c l-2$ or $B c l-6$ translocation) or triple-hit lymphoma (when all 3 translocations are present) [15]. Mitelman database revealed that $62 \%$ of these newly categorized $M Y C$-rearranged lymphomas involve $b c l-2$ translocations, $18 \%$ involve $b c l-6$ translocations, and the remaining cases are triple-hit lymphomas [16]. Further, the specific translocation partner of $M Y C$ impacts outcome, with immunoglobulin gene translocations conferring the shortest survival time [17].

\section{Evaluation of double, triple hit lymphoma patients}

Patients with double or triple hit should undergo routine evaluation by CT/PET scans in order to make a good staging. A bone marrow aspiration and biopsy, $\mathrm{LDH}$, renal and hepatic function. Since $10 \%$ of cases are presented with central nervous system involvement especially in those with $M Y C$ rearrangement, a lumber puncture is recommended and sample to be evaluated by a more sensitive test like Flowcytometry [18].

\section{What impact these hits have on treatment outcome?}

Unfortunately, there are no published prospective trials in the setting of double-hit lymphoma. Further, the response is very poor using the conventional protocol of $\mathrm{R}-\mathrm{CHOP}$ and most patients experience disease progression, therefore, researchers tend to use protocols employed in Burkitt lymphoma treatment such as Hypercvad and CODOX-M/IVAC. The former protocols demonstrated good results in Burkitt lymphoma treatment were $M Y C$ plays a major role in pathogenesis as well [19]. However, is this approach is sufficient to employ those protocols? Trials were conducted using CODOX followed by high-dose chemotherapy and autologous stem cell transplantation. Only $44 \%$ of patients who started the regimen remained in remission at 2 years, with early progressions precluding ASCT in $41 \%$ of patients [20]. Another trial randomized patients to undergo either 8 cycles of R-CHOP or 6 cycles of R-CHOP followed by ASCT. Lymphomas with $M Y C$ expression were morphologically and phenotypically heterogeneous and were associated with poor progression-free and overall survival in multivariate analysis. All patients with double-hit lymphoma died whether or not they received ASCT [21]. Another report from MD Anderson cancer center showed two-years event-free survival rates in patients who received $\mathrm{R}-\mathrm{CHOP}$, $\mathrm{R}-\mathrm{EPOCH}$, and R-HyperCVAD/MA were $25 \%, 67 \%$, and $32 \%$, respectively [22].

Prospective trials are still needed to conclude that R-EPOCH is better than R-CHOP in the treatment of double hit lymphoma. However, the German lymphoma foundation showed that intensified R-CHOP-14 is slightly similar to R-EPOCH in younger patients with aggressive B-cell lymphoma.

\section{Results and Discussion}

First of all, double hit and/or triple hit lymphoma is considered a syndrome rather than a disease. Several mechanisms are implicated in its pathogenesis, one of them, is $M Y C$ rearrangement which confer a high load of transcription factors activity leading to an increase in the mitotic rate and consequently aggressiveness of the disease course. Another mechanism is the alteration of BCL6 or/and BCL-2 status which provoke the oncogenic activity of both genes. CD20 is another player detected on the surface of B-cell lymphocyte which plays a role in lymphocyte division through receiving growth factor signals. In brief, we notice that there are several factors implicated in the pathogenesis of double hit lymphoma and we can imagine the cross talk between those different factors. Further, with the existence of active $M Y C$ and $B C L 6$, most patients may demonstrate resistance to anti-CD20 therapy like Rituximab, the thing that raise an important question which need to be answered soon, can we continue Rituximab if there is no response or/and there is progression on the first 3 cycles of R-CHOP or R-EPOCH?

Researchers around the world use protocols already used to treat Burkitt lymphoma such as HYPERCVAD and CODOX for one reason only ( $M Y C$ does exist in both Burkitt lymphoma and double hit lymphoma). Is this approach is right? In fact, we cannot give a definitive answer because the pathogenesis of Burkitt lymphoma is entirely different taking into account the high tumor burden, high white blood cell count and the domination of CD19. It is true that $M Y C$ is detected in Burkitt, however, it plays a different function. In double hit lymphoma, there is a synergistic effect between $M Y C, B C L 6$ or/and BCL-2 as well as CD20, and every one of them draw its own gray zone in the field of diffuse large B-cell lymphoma. So, the space DLBCL occupies is decreasing day after day with the emergence of new oncogenes leading this lymphoma to a more unexpected aggressive course.

\section{Conclusion}

In clinical practice, R-EPOCH is found to be much more better than HYPERCVAD especially in elderly patients because it is much more tolerable as illustrated a study conducted by US intergroup [23]. Intrathecal Methotrexate is kept only for patients presenting with high tumor burden, high LDH level and those presenting with lesions on the head and extranodal sites. Another intensified protocol such as 
Citation: Salamoon M (2018) BCL6/BCL2 and MYC Alterations Drawing the Gray Zone between Diffuse Large B-cell Lymphoma and Double, Triple Hit Lymphoma. J Mol Genet Med 12: 336. doi:10.4172/1747-0862.1000336

Page 3 of 3

HYPERCVAD is a good choice in young patients; however it is not demonstrating a good response on the long term [23].

Finally, there is no standard of care for the treatment of double hit lymphoma so far; therefore, researchers are invited to a more scientific investment in the treatment of this challenging disease.

\section{Disclosure}

I declare no conflict of interest.

\section{References}

1. Stein H, Warnke RA, Chan WC, Swerdlow SC, Campo E, et al. (2008) Diffuse large B-cell lymphoma, not otherwise specified In: WHO Classification of Tumours of Haematopoietic and Lymphoid Tissues. IARC 1: 233-237.

2. Chan WJ (2010) Pathogenesis of diffuse large B cell lymphoma. Int J Hematol 92: 219-230.

3. Alizadeh AA, Eisen MB, Davis RE, Ma C, Lossos IS, et al. (2000) Distinct types of diffuse large B-cell lymphoma identified by gene expression profiling. Nature 403: 503-511.

4. Rosenwald A, Wright G, Chan WC, Connors JM, Campo E, et al. (2002) The use of molecular profiling to predict survival after chemotherapy for diffuse large-B-cell lymphoma. N Engl J Med 346: 1937-1947.

5. Wright G, Tan B, Rosenwald A, Hurt EH, Wiestner A, et al. (2003) A gene expression-based method to diagnose clinically distinct subgroups of diffuse large B cell lymphoma. Proc Natl Acad Sci 100: 9991-9996.

6. Ueda C, Nishikori M, Kitawaki T, Uchiyama T, Ohno H (2004) Coexistent rearrangements of c- $M Y C, B C L 2$, and $B C L 6$ genes in a diffuse large B-cell lymphoma. Int J Hematol 79: 52-54.

7. Aukema SM, Siebert R, Schuuring E (2011) Double-hit B-cell lymphomas. Blood 117: 2319-2331.

8. Akyurek N, Uner A, Benekli M, Barista I (2012) Prognostic significance of $M Y C, B C L 2$, and $B C L 6$ rearrangements in patients with diffuse large B-cell lymphoma treated with cyclophosphamide, doxorubicin, vincristine and prednisone plus rituximab. Cancer 118: 4173-4183.

9. Kramer MH, Hermans J, Wijburg E, Philippo K, Geelen E, et al. (1998) Clinical relevance of $B C L 2, B C L 6$, and $M Y C$ rearrangements in diffuse large B-cell lymphoma. Blood 92: 3152-3162.

10. Perkins AS, Friedberg JW (2008) Burkitt lymphoma in adults. Hematology 2008: 341-348.

11. Aukema S, Siebert R, Schuuring E (2011) Double-hit B-cell lymphomas. Blood. 24: 2319-2331.
12. Dunleavy K, Pittaluga S, Wayne A (2011) $M Y C+$ aggressive-B-cell lymphomas: novel therapy of untreated Burekitt (BL) and $M Y C+$ diffuse large B-cell lymphoma (DLBCL with DA-EPOCH-B. Ann Oncol 22: 071011-ICML

13. Swerdlow SH, Campo E, Pileri SA (2016) The 2016 revision of the World Health Organization classification of lymphoid neoplasms. Blood 127: 2375-2390.

14. Friedberg JW (2012) Double-hit diffuse large B-cell lymphoma. J Clin Oncol 30: 3439-3443.

15. Aukema SM, Siebert R, Schuuring E (2011) Double-hit B-cell lymphomas. Blood 117: 2319-2331.

16. Bergman CC, Gaulard P, Leroy K (2009) Immuno-fluorescence in situ hybridization index predicts survival in patients with diffuse large B-cell lymphoma treated with R-CHOP: A GELA study. J Clin Oncol 27: 5573-5579.

17. Hegde U, Filie A, Little RF (2005) High incidence of occult leptomeningeal disease detected by flow cytometry in newly diagnosed aggressive B-cell lymphomas at risk for central nervous system involvement: the role of flow cytometry versus cytology. Blood 105: 496-502.

18. Magrath I, Adde M, Shad A (1996) Adults and children with small noncleaved-cell lymphoma have a similar excellent outcome when treated with the same chemotherapy regimen. J Clin Oncol 14: 925-934.

19. Sun H, Savage KJ, Karsan A (2015) Outcome of patients with nonhodgkin lymphomas with concurrent $M Y C$ and BCL2 rearrangements treated with CODOX-M/IVAC with rituximab followed by hematopoietic stem cell transplantation. Clin Lymphoma Myeloma Leuk 15: 341-348.

20. Puvvada SD, Stiff PJ, Leblanc M, Cook JR, Couban S, et al. (2016) Outcomes of $M Y C$-associated lymphomas after R-CHOP with and without consolidative autologous stem cell transplant: A subset analysis of randomized trial intergroup SWOG S9704. Br J Haematol 174: 686-691.

21. Oki Y, Noorani M, Lin P, Davis RE, Neelapu SS, et al. (2014) Double hit lymphoma: The MD Anderson Cancer Center clinical experience. Br J Haematol 166: 891-901.

22. Duleavy K, Fanale M, Lacasce A (2014) Preliminary report of a multicenter prospective phase-II study of DA-EPOCH-R in MYCrearranged aggressive B-cell lymphoma. Blood 124: 395.

23. Schmitz N, Zeynalova S, Nickelsen M, Kansara R, Villa D, et al. (2016) CNS International Prognostic Index: A risk model for CNS relapse in patients with diffuse large B-cell lymphoma treated with R-CHOP. J Clin Oncol 34: 3150-3156. 